\title{
Editorial
}

\section{Emerging Issues in Occupational Safety and Health}

\author{
Kapo Wong and Alan Hoi Shou Chan * \\ Department of Systems Engineering and Engineering Management, City University of Hong Kong, \\ Tat Chee Avenue, Kowloon, Hong Kong, China; kpwong42-c@my.cityu.edu.hk \\ * Correspondence: meachan@cityu.edu.hk; Tel.: +852-3442-8439
}

Received: 12 December 2018; Accepted: 14 December 2018; Published: 18 December 2018

Working environments have various risks, which result in accidents and casualties. To prevent and minimize the occurrence of avoidable accidents, all workers should understand occupational safety and health. The principle of occupational safety and health is to safeguard the safety and health of workers through the establishment of a safe working environment. The protection of occupational safety and health involves multitudinous categories, such as ergonomics, toxicology, physics, chemistry, and economics. The concern for the occupational safety and health of workers focuses not only on their physical health but also on mental health. Mental health refers to the well-being of an individual. Poor mental health may be a predictor of physical health problems and people with physical illnesses have a high tendency of suffering from depression and distress [1]. However, according to a survey conducted by Safety and Health Magazine in 2018, about 50\% of the respondents thought that mental health should not be counted as part of occupational safety and health [2]. In fact, mental health is part and parcel of occupational safety and health [3,4]. No matter what types of occupational diseases and illnesses workers experience, deleterious effects will be generated, for example, low productivity [5], high rates of absenteeism [6], and economic loss for companies [7]. Furthermore, dynamic and changing working environments result in many unknown risks, which pose challenges and opportunities for workers, organisations, and authorities. Therefore, potential risks in working environments should be eliminated by identifying factors affecting risk-taking behaviour and the mental and physical health of workers, pertinent health measures, approaches on occupational safety and health in organisations, and government legislation. The published papers in the Special Issue on "Emerging Issues in Occupational Safety and Health" cover all these important and eminent issues.

To identify factors affecting the risk-taking behaviour of workers, several studies have investigated the reasons why they conduct such behaviour [8-13]. Factors influencing the risk-taking propensity of workers include safety supervision and inspection, safety culture of working environments, social influence, workplace conditions, attitude of workers towards risk, risk perception, and self-perceived easiness of risk-taking behaviour [8,9]. Jiang and Han [10] report that the preconditions for unsafe acts, unsafe supervision, and organisational influences resulted in unsafe behaviour. Larsson et al. [11] demonstrate that the safety perception of workers was influenced by safe working environments, leadership, prioritising safety at work, and provision of trust, and support by management. Tong et al. [12] explore human risk factors affecting risk-taking behaviour through coal mining roof accidents in China; such factors include knowledge, information, communication, and performance and behaviour of senior managers. Thamrin et al. [13] identify inadequate safety training, long working hours (more than $20 \mathrm{~h}$ per week), and insufficient confidence on the discussion of safety issues as the main factors resulting in injuries. Therefore, the awareness and consciousness on occupational safety and health should be enhanced by improving these identified areas to avoid performing unsafe behaviour that will adversely affect the physical and mental health of workers. 
The physical and mental health problems of workers can tremendously affect their work performance. Numerous factors can lead to physical and psychological occupational diseases and illnesses [14-22]. Kim and Cho [19] find that Korean workers with a high demand on childcare easily contracted musculoskeletal disorders and had problems with work-life conflicts. High concentrations of asbestos in factories threaten health of workers and cause a number of deaths and disabilities every year [17]. Molino et al. [22] point out a negative relationship between exhaustion and recovery among workaholism. According to a cluster analysis of high-frequency words with long working hours as the core theme [20], physiological health problems are not the main aspect that causes the burnout of workers, and psychological distress has gradually become the primary concern. Job stress is one of the prevailing psychological diseases and negatively influences the performance of workers [14]. Junne et al. [16] also state that stress is a "pandemic" disease among workers in Germany and suggest that different sectors should cooperate to improve the mental health of workers. However, Ma et al. [21] note that an appropriate amount of challenge stress should be put onto workers to ameliorate worker quality. Furthermore, female workers experience more health problems and lower psychological well-being than male workers [15]. Female workers also have a higher incidence of symptomatic cervical and lumbar disc herniation compared with male workers [18]. All these studies in this Special Issue reveal that the influences of physical and mental health problems cannot be neglected; thus, measures should be developed for evaluation of the health status and work performance of workers to reduce unnecessary accidents and risks.

Sensitive and quick measures should be developed to effectively assess the health condition of workers and minimize the severity level of certain occupational health problems. Fatigue is one of the hidden syndromes of many diseases. Duan et al. [23] introduced a mental fatigue detection index to alert workers of whether they suffer from chronic exhaustion and propose countermeasures to alleviate this problem. Job stress is a concerned psychological health problem among most workers. To measure the job stress of workers, Wu et al. [24] developed a job stress scale for construction workers in China given that job stress causes different types of unsafe behaviour in the construction industry. A number of work performance measures were also developed to appraise the capability of workers. Job satisfaction measurements were proposed to identify several facet items, such as stress and work engagement $[25,26]$. The Work Ability Index was used to predict the work performance of workers for work design and improvement [27]. These measures may be able to resolve the instant health problems of workers while appropriate strategies and policies should be formulated to address related health issues.

Other than the efforts of workers and researchers, the work organisation should establish a positive, safe culture in the working environment. Wagner et al. [28] suggest that the existence of worker safety culture is not sufficient and patient safety culture should be incorporated to develop a safe working environment in hospitals. Governments and organisations should offer continuing education and training for workers to deepen their consciousness on occupational safety and health and provide compensation for victims [14,29]. Legislation and guidance protocols should be implemented to address the safety and health issues of workers [30]. Undeniably, a considerable amount of direct costs and indirect costs are involved for all of these actions [7,31]. However, in the long run, the safety and health of workers can be safeguarded, thereby reducing absenteeism and turnover rates, increasing the attraction of talent and goodwill of companies, enhancing worker motivation and organisation commitment, and reducing costs on healthcare and social insurance.

Author Contributions: K.W. and A.H.S.C. conceived the article and participated to write and revise the manuscript.

Funding: This research received no external funding.

Conflicts of Interest: The authors declare no conflict of interest. 


\section{References}

1. Collingwood, J. The Relationship between Mental and Physical Health; Psych Central: Newburyport, MA, USA, 2018; Available online: https:/ / psychcentral.com/lib/the-relationship-between-mental-and-physicalhealth/ (accessed on 7 December 2018).

2. What's Your Opinion: Should Mental Health in the Workplace Be Part of the Safety Pro's Responsibility? Safety and Health Magazine, 6 June 2018. Available online: https:/ / www.safetyandhealthmagazine.com/ articles/17122-should-mental-health-in-the-workplace-be-part-of-the-safety-pros-responsibility (accessed on 7 December 2018).

3. Danna, K.; Griffin, R.W. Health and Well-Being in the Workplace: A Review and Synthesis of the Literature. J. Manag. 1999, 25, 357-384. [CrossRef]

4. Quick, J.C.; Murphy, L.R.; Hurrell, J.J., Jr. (Eds.) Stress \& Well-Being at Work: Assessments and Interventions for Occupational Mental Health; American Psychological Association: Washington, DC, USA, 1992.

5. Oxenburgh, M.; Marlow, P. The Productivity Assessment Tool: Computer-based cost benefit analysis model for the economic assessment of occupational health and safety interventions in the workplace. J. Saf. Res. 2005, 36, 209-214. [CrossRef] [PubMed]

6. Cocker, F.; Martin, A.; Scott, J.; Venn, A.; Sanderson, K. Psychological Distress, Related Work Attendance, and Productivity Loss in Small-to-Medium Enterprise Owner/Managers. Int. J. Environ. Res. Public Health 2013, 10, 5062-5082. [CrossRef] [PubMed]

7. Steel, J.; Godderis, L.; Luyten, J. Methodological Challenges in the Economic Evaluation of Occupational Health and Safety Programmes. Int. J. Environ. Res. Public Health 2018, 15, 2606. [CrossRef] [PubMed]

8. Low, B.K.L.; Man, S.S.; Chan, A.H.S. The Risk-Taking Propensity of Construction Workers-An Application of Quasi-Expert Interview. Int. J. Environ. Res. Public Health 2018, 15, 2250. [CrossRef] [PubMed]

9. Wagner, A.; Michaelis, M.; Luntz, E.; Wittich, A.; Schrappe, M.; Lessing, C.; Rieger, M.A. Assessment of Patient and Occupational Safety Culture in Hospitals: Development of a Questionnaire with Comparable Dimensions and Results of a Feasibility Study in a German University Hospital. Int. J. Environ. Res. Public Health 2018, 15, 2625. [CrossRef] [PubMed]

10. Jiang, W.; Han, W. Analysis of "2.28" KEEPER Chemical Industries Hazardous Chemical Explosion Accident Based on FTA and HFACS. Int. J. Environ. Res. Public Health 2018, 15, 2151. [CrossRef] [PubMed]

11. Larsson, A.; Westerberg, M.; Karlqvist, L.; Gard, G. Teamwork and Safety Climate in Homecare: A Mixed Method Study. Int. J. Environ. Res. Public Health 2018, 15, 2495. [CrossRef] [PubMed]

12. Tong, R.; Zhai, C.; Jia, Q.; Wu, C.; Liu, Y.; Xue, S. An Interactive Model among Potential Human Risk Factors: 331 Cases of Coal Mine Roof Accidents in China. Int. J. Environ. Res. Public Health 2018, 15, 1144. [CrossRef] [PubMed]

13. Thamrin, Y.; Pisaniello, D.; Guerin, C.; Rothmore, P. The Emerging Workforce of International University Student Workers: Injury Experience in an Australian University. Int. J. Environ. Res. Public Health 2018, 15, 456. [CrossRef] [PubMed]

14. Chan, I.Y.S.; Leung, M.-Y.; Liang, Q. The Roles of Motivation and Coping Behaviours in Managing Stress: Qualitative Interview Study of Hong Kong Expatriate Construction Professionals in Mainland China. Int. J. Environ. Res. Public Health 2018, 15, 561. [CrossRef] [PubMed]

15. Gómez-Baya, D.; Lucia-Casademunt, A.M.; Salinas-Pérez, J.A. Gender Differences in Psychological Well-Being and Health Problems among European Health Professionals: Analysis of Psychological Basic Needs and Job Satisfaction. Int. J. Environ. Res. Public Health 2018, 15, 1474. [CrossRef] [PubMed]

16. Junne, F.; Michaelis, M.; Rothermund, E.; Stuber, F.; Gündel, H.; Zipfel, S.; Rieger, M.A. The Role of Work-Related Factors in the Development of Psychological Distress and Associated Mental Disorders: Differential Views of Human Resource Managers, Occupational Physicians, Primary Care Physicians and Psychotherapists in Germany. Int. J. Environ. Res. Public Health 2018, 15, 559. [CrossRef] [PubMed]

17. Kang, D.; Hwang, Y.; Choi, Y.; Kim, S.-Y.; Kim, Y.-K. Monitoring and Simulating Environmental Asbestos Dispersion from a Textile Factory. Int. J. Environ. Res. Public Health 2018, 15, 1398. [CrossRef] [PubMed]

18. Kim, Y.-K.; Kang, D.; Lee, I.; Kim, S.-Y. Differences in the Incidence of Symptomatic Cervical and Lumbar Disc Herniation According to Age, Sex and National Health Insurance Eligibility: A Pilot Study on the Disease's Association with Work. Int. J. Environ. Res. Public Health 2018, 15, 2094. [CrossRef] [PubMed] 
19. Kim, Y.-M.; Cho, S.-I. Associations of Family Demands and Work-Life Conflict with Musculoskeletal Disorders among Korean Workers. Int. J. Environ. Res. Public Health 2018, 15, 1419. [CrossRef] [PubMed]

20. Liu, B.; Chen, H.; Huang, X. Map Changes and Theme Evolution in Work Hours: A Co-Word Analysis. Int. J. Environ. Res. Public Health 2018, 15, 1039. [CrossRef] [PubMed]

21. Ma, T.; Yang, T.; Guo, Y.; Wang, Y.; Deng, J. Do Challenge Stress and Hindrance Stress Affect Quality of Health Care? Empirical Evidence from China. Int. J. Environ. Res. Public Health 2018, 15, 1628. [CrossRef] [PubMed]

22. Molino, M.; Cortese, C.G.; Ghislieri, C. Daily Effect of Recovery on Exhaustion: A Cross-Level Interaction Effect of Workaholism. Int. J. Environ. Res. Public Health 2018, 15, 1920. [CrossRef] [PubMed]

23. Duan, T.; Zhang, N.; Li, K.; Hou, X.; Pei, J. Study on the Preferred Application-Oriented Index for Mental Fatigue Detection. Int. J. Environ. Res. Public Health 2018, 15, 2555. [CrossRef] [PubMed]

24. Wu, X.; Li, Y.; Yao, Y.; Luo, X.; He, X.; Yin, W. Development of Construction Workers Job Stress Scale to Study and the Relationship between Job Stress and Safety Behavior: An Empirical Study in Beijing. Int. J. Environ. Res. Public Health 2018, 15, 2409. [CrossRef] [PubMed]

25. Lepold, A.; Tanzer, N.; Bregenzer, A.; Jiménez, P. The Efficient Measurement of Job Satisfaction: Facet-Items versus Facet Scales. Int. J. Environ. Res. Public Health 2018, 15, 1362. [CrossRef] [PubMed]

26. Zhang, W.; Meng, H.; Yang, S.; Liu, D. The Influence of Professional Identity, Job Satisfaction, and Work Engagement on Turnover Intention among Township Health Inspectors in China. Int. J. Environ. Res. Public Health 2018, 15, 988. [CrossRef] [PubMed]

27. Ng, J.Y.K.; Chan, A.H.S. The Work Ability of Hong Kong Construction Workers in Relation to Individual and Work-Related Factors. Int. J. Environ. Res. Public Health 2018, 15, 990. [CrossRef] [PubMed]

28. Wagner, A.; Hammer, A.; Manser, T.; Martus, P.; Sturm, H.; Rieger, M.A. Do Occupational and Patient Safety Culture in Hospitals Share Predictors in the Field of Psychosocial Working Conditions? Findings from a Cross-Sectional Study in German University Hospitals. Int. J. Environ. Res. Public Health 2018, 15, 2131. [CrossRef] [PubMed]

29. Zhou, H.; Han, X.; Zhang, J.; Sun, J.; Hu, L.; Hu, G.; Wu, S.; Zhao, P.; Jiang, F.; Liu, Y. Job Satisfaction and Associated Factors among Medical Staff in Tertiary Public Hospitals: Results from a National Cross-Sectional Survey in China. Int. J. Environ. Res. Public Health 2018, 15, 1528. [CrossRef] [PubMed]

30. Vuorio, A.; Budowle, B.; Sajantila, A.; Laukkala, T.; Junttila, I.; Kravik, S.E.; Griffiths, R. Duty of Notification and Aviation Safety-A Study of Fatal Aviation Accidents in the United States in 2015. Int. J. Environ. Res. Public Health 2018, 15, 1258. [CrossRef] [PubMed]

31. Li, S.; Chen, H.; Huang, X.; Long, R. Who Has Higher Willingness to Pay for Occupational Safety and Health?-Views from Groups with Different Public Identities and Differences in Attention. Int. J. Environ. Res. Public Health 2018, 15, 1667. [CrossRef] [PubMed]

(C) 2018 by the authors. Licensee MDPI, Basel, Switzerland. This article is an open access article distributed under the terms and conditions of the Creative Commons Attribution (CC BY) license (http:/ / creativecommons.org/licenses/by/4.0/). 